\title{
The impact of online platform transparency of information on consumer's choices
}

\section{Authors:}

Giuseppe A. Veltri, PhD (corresponding author)

Affiliations: Associate Professor, University of Trento, Department of Sociology and Social Research, Italy

Email: giuseppe.veltri@unitn.it

Francisco Lupiáñez-Villanueva, $\mathrm{PhD}$

Affiliations: Professor, Universitat Oberta de Catalunya, Department of Information and Communication Science. Open Evidence Research, Barcelona, Spain.

Frans Folkvord, $\mathrm{PhD}$

Affiliations: Senior Policy Researcher, Universitat Oberta de Catalunya, Open Evidence Research, Barcelona, Spain.

Assistant Professor, Tilburg School of Humanities and Digital Sciences, Tilburg University, Tilburg, The Netherlands

Alexandra Theben

Affiliations: Phd Candidate, Universitat Oberta de Catalunya, Open Evidence Research, Barcelona, Spain.

George Gaskell, PhD

Affiliations: Professor, London School of Economics and Political Science, UK.

\section{Disclaimer}

This manuscript was produced based on a study funded under the EU Consumer Programme (2014-2020) in the frame of a specific contract with the Consumers, Health, Agriculture and Food Executive Agency (Chafea) acting on behalf of the European Commission. The content of this manuscript represents the views of the authors and is its sole responsibility; it can in no way be taken to reflect the views of the European Commission and/or Chafea or any other body of the European Union. The European Commission and/or Chafea do not guarantee the accuracy of the data included in this manuscript, nor do they accept responsibility for any use made by third parties thereof. 
Forthcoming in Behavioural Public Policy (BPP) - Pre-print - Not final Proof

\section{Abstract}

Millions of Europeans use online platforms with almost blind trust that the platforms operate in the interests of the consumer. However, the presentation of search results, transparency about contractual parties and the publication of user reviews that contribute to the value of online platforms in Europe's Single Digital Market also pose significant risks regarding consumer protection and market competition. The current study investigates how enhanced information transparency in online platforms might affect consumers' trust in online activities and choice behaviour.

Following an exploratory qualitative study, three online discrete choice experiments were conducted with representative samples of 1200 respondents in each of four countries - Germany, Poland, Spain and the UK. The objective of the experiments was to test whether increased transparency in the presentation of online search information, details of contractual entities and the implications for consumer protection, and user reviews and ratings would affect consumers' choices. The results show that increased online transparency increases the probability of product selection. A comparison across the four countries found that the similarities in responses to online transparency were far greater than the differences. The findings are discussed in relation to biases and heuristics identified in behavioural science. In conclusion recommendations are made to increase online transparency which the empirical evidence of this study shows would benefit both users and platform operators.

Keywords: Online transparency, Discrete Choice, contractual identity, user reviews, search information. 
Forthcoming in Behavioural Public Policy (BPP) - Pre-print - Not final Proof

\section{Introduction}

The European Commission's Work Programme 2018 (COM/2017/0650) emphasised the importance of the Digital Single Market and set out the New Deal for Consumers, stating that the success of the internal market ultimately depends on trust and that trust can easily be lost if consumers feel that remedies are not available in cases of harm.

The current study was a contribution to the evidence reviewed by the Commission in the regulatory Fitness Check of EU Consumer and Marketing Law concerning online platforms. Within this framework, the characteristics of online platforms in terms of the criteria guiding the presentation of searched information, transparency regarding contractual entities and users' reviews were seen as having important consequences for consumers. The platforms provide a service to the users, access to goods and products. Thus, at a general level, the question arises as to what extent the service provided by online platforms is balanced in the interests of the users or balanced in the interests of the platform. More concretely, if in an online search, the criteria for the ranking of providers of goods and services is not transparent and is designed to maximise advertising revenue for the platform, then this might constitute an unfair commercial practice. Similarly, if consumers are intentionally misled to the extent that they do not know who is their "contractual counterpart", or who they have to deal with in case of any contractual questions, this constitutes an unfair commercial practice. The same holds true for the risk of manipulating consumer opinion through the presentation or transparency of reviews and ratings, including fake reviews. At the heart of all these aspects is the issue of trust and transparency in platforms. Trusting that the platform has the users' interests in mind, and confidence that the information provided is unbiased allows the consumer to make an informed choice.

The success of the Digital Single Market ultimately depends on the confidence and trust of Europeans. As the use of online platforms has reached unprecedented levels, the potential of online platforms to generate economic growth as drivers of innovation remains undisputed. However, the growing importance of online platforms and their expansion into new areas of the economy has given rise to new challenges. 
The overall purpose of this behavioural study on the transparency of online platforms was to understand the impact of enhanced transparency on consumer trust and behaviour in searching for and selecting goods and services on online platforms in three specific areas:

1: The criteria used by platform operators to present search results to users, in which order, and at what level of saliency

2: The identity and the legal status of the contracting parties involved in transactions enabled or facilitated by the platforms. For example, whether the consumer would be entering a contract with the platform provider or some other retailer or service provider and whether that person is acting as a trader within the meaning of EU consumer law or not.

3: The quality controls established by platform operators (or lack thereof) on user reviews, ratings and endorsement systems. For example, verification of origin and authenticity, incentives linked to entries, screening / censorship, and the right to rebuttal of affected parties.

The study comprised a systematic review of the literature, an in-depth 'think aloud' online qualitative enquiry, and three discrete choice behavioural experiments.

\section{Literature review}

Search information

The articles identified in the systematic literature review address the impact of information display (Ma, Liu, and Hossain, 2013; Rieder and Sire, 2014; Sonntag, 2015; Ursu, 2018); search results position (Baye, De los Santos and Wildenbeest, 2016; Chen and He, 2011; Jerath, Ma and Park, 2014; Kulkarni, Kannan and Moe, 2012); trust (Jeacle and Carter, 2011) and review manipulation (Luca et al., 2015). According to Ma et al. (2012), search engines play a critical role in the diffusion of online information as they determine what content is available to internet users. Major search engines, such as Google, Microsoft Live Search, and Yahoo!, provide two distinct types of results, organic and paid, each of which uses different mechanisms for selecting and ranking relevant Web pages. 
Findings by Baye, de los Santos \& Wildenbeet (2016) suggest that that a retailer's rank on a results page is an important driver of its organic clicks. That is, holding other drivers of clicks constant, consumers tend to click retailers that are more recognised, trusted, have reputations for providing value (in terms of price, product depth, or breadth), and service (well-designed web sites, return policies, secure payment systems). Unsurprisingly, paid placement, where advertisers bid payments to a search engine to have their products displayed prominently among the results of a keyword search, has emerged as a dominant form of advertising on the internet (Chen \& He, 2011). Luca et al. (2015) find that, while Google is known primarily as a search engine, it has increasingly developed and promoted its own content as an alternative to results from other websites. By prominently displaying Google content in response to search queries, Google is able to use its dominance in search to gain customers for this content, which may potentially lead to reduced consumer welfare if the internal content is inferior to organic search results.

An experiment conducted by Ma, Liu \& Hossain (2013) on consumer trust and purchase choice from vendors listed in organic and sponsored search results suggests trust is lower for sponsored links compared to organic links, and that consumers are less likely to buy from vendors in sponsored search results. However, the disclosure of information about vendors' reliability reduces this negative effect. This highlights the importance of ensuring that the "organic results" are ranked according to relevance to the user, and not driven by the platforms' corporate or financial interests. Specifically, disclosing vendors' reliability ratings helps increases consumers trust to sponsored results.

\section{Identity of contractual parties}

The identification of the contractual parties has traditionally served to ensure trust and credibility among exchange partners (Flanagin et al. 2011). Consumer trust is identified as one of the most important features in electronic commerce growth. For example, Kim \& Gupta (2012) suggest that consumer trust in a website or service is more important than the product or price offered, as no 
matter how low the price offered the authentication of the website or online supplier is more influential. Hong and Cho (2011), argue that consumers' trust in one aspect of the online marketplace generalises to other features and influences online purchases.

Beyond the issue of trust, online transparency is of particular relevance to provisions of European Unfair Commercial Practices Directive. This stipulates that a trader in an online platform is required to act with a degree of professional diligence commensurate to its specific field of activity and honest market practice, and not to mislead their users/consumers by either action or omission. Platforms should, therefore, take appropriate measures to enable users to clearly understand with whom they are concluding contracts. The crux of the issue is that platform users will only benefit from protection under EU consumer and marketing laws in their dealings with contractual parties (sellers) who are traders. With sellers not operating as traders it is a case of 'caveat emptor'; there is no consumer protection should the service or product be deficient in any way or form.

\section{User reviews}

Internet users increasingly rely on product reviews and ratings provided by other consumers (Agnihotri \& Bhattacharya 2016; Baek, Ahn \& Choi 2012; Malbon 2013;). Llamero (2014) reports that only so-called "electronic-word-of-mouth" (eWOM) consumer reviews are seen as credible, suggesting that reviewing is based on limited sources. Ballantine \& Yeung (2015) postulate that consumers seeking eWOM often use heuristic cues to assess the credibility of online information. In particular, content characteristics are one of the main factors determining trust in eWOMs.

To understand the perceptions of the credibility of commercial website information and the factors users find important in their evaluative processes, Flanagin et al. (2011) conducted a nationally representative survey and quasi-experiment. The survey finds that while people engage in online marketplaces regularly, they seldom contribute to the review process. They do, however, rely heavily on ratings to evaluate the credibility of online commercial information. Experimental results further indicate that people tend to aggregate product ratings, but not to assess the number of ratings when evaluating the quality of products sold online. As suggested by Baek, Ahn \& Choi (2015) the influx 
of online consumer reviews has created information overload, making it difficult for consumers to choose reliable reviews.

Online reviews could, in principle, greatly improve consumers' ability to evaluate products (Mayzlin, Dover \& Chevalier 2012). However, the authenticity of online user reviews remains a concern as traders and non-traders have an incentive to manufacture positive reviews for their own products and negative reviews for their rivals. Mayzlin, Dover \& Chevalier (2014) provide an empirical analysis of promotional reviews, examining both the extent to which fakery occurs and the market conditions that encourage or discourage promotional reviewing activity in two travel websites: Expedia.com and TripAdvisor.com. In this regard, some of the features applied by websites can be important. For example, while anyone can post a review on TripAdvisor, only those who have spent at least one night at the hotel and have booked through the website can only post a review of a hotel on Expedia. In this context, Kusumasondjaja, Shanka, \& Marchegiani (2012) investigate the effects of review valence and the presence of source identity on consumer perceptions of the review credibility and trust in the travel services being reviewed. Results indicate that a negative online review is deemed more credible than a positive review, while a positive review leads to a greater initial trust than a negative review. These findings apply when the identity of the reviewer is disclosed. However, when the reviewer's identity is not disclosed, there is no significant difference between positive and negative reviews either in terms of perceived credibility or impact on consumer trust.

According to Filieri (2015), the proliferation of fake and paid online reviews means that building and maintaining consumer trust is a challenging task for websites hosting consumer-generated content. Fake consumer reviews are found to undermine a (potentially) effective and efficient mechanism for overcoming information asymmetry between online sellers and buyers (Malbon, 2013). Consumer reviews also offer a powerful mechanism for regulating the marketplace. Genuine consumer reviews can moderate bad seller behaviour and assist in improving the quality and efficiency of the marketplace. Although there are laws in many jurisdictions that prohibit misleading and deceptive conduct, detecting fake reviews is complex. It has been suggested that it should be addressed by 
Forthcoming in Behavioural Public Policy (BPP) - Pre-print - Not final Proof

regulators through an 'alliance approach', bringing soft power to achieve a fair and competitive marketplace.

\section{An In-depth exploratory study}

A small scale qualitative study was conducted to gain a better understanding of how experienced and less experienced online participants use and think about online platforms. One objective of this exploratory study was to ensure that the design of the forthcoming experiments on the impact of greater transparency and in particular the choice of interventions reflected, as far as possible, the everyday reality of online consumers. The procedure adopted was a set of 'think aloud' online tasks with 10 participants in each of four countries - Spain, UK, Germany, Poland. Accompanied by a social researcher, the respondents talked through the completion of a three of online tasks information searches, a simulated purchase and an assessment of user reviews. The researcher observed the respondent's behaviour and conducted an in-depth interview about their experience, and on the internet in general.

With the small numbers of respondents in this qualitative study it is necessary to be cautious in drawing conclusions. Insights that informed our experimental studies are as follows.

Respondents were far more concerned with the speed and convenience of their search than with issues of transparency or potential manipulation. Results showed that generally, participants felt that the order of the results presented was based on popularity, i.e. number of previous clicks. The ranking of search results or advertising was not considered to exploit them. Rather, it was perceived as a source of revenue for the websites. Some level of 'manipulation' of search results was seen as just a part of how business works. Respondents were often unware of issues related to contractual parties. They tend to trust platforms that are recognized and well-known. Consumers willingly buy from unknown traders in online marketplaces, since they trust the institutional mechanisms behind the platforms. Respondents acknowledged that websites cannot be held responsible for the reliability of reviews. While the platforms were trusted, user reviews were seen as likely to be open to manipulation. Negative reviews were generally seen as more credible than positive reviews and a high number of 
Forthcoming in Behavioural Public Policy (BPP) - Pre-print - Not final Proof

reviews gave a kind of guarantee that potential biased comments were compensated by authentic ones.

\section{Experimental methodology}

The outcome of this preparatory phase informed the design of three discrete choice experiments testing the impact of transparency in information provision on the choice behaviour of respondents in online searches; the identity of contractual parties (sellers), and user reviews and ratings.

The discrete choice methodology is a quantitative technique for eliciting preferences and identifying the relative importance of different attributes of a product or service in the consumer decision-making process. A discrete choice experiment consists of a series of binary choices between pairs of products made up of different attributes and levels of these attributes. The goods and services offered were (1) booking of a restaurant (information search), (2) purchasing a smartphone (contractual identity), and (3): booking of a hotel (user reviews).

Sample characteristics

The sample for the experiment consisted of 4,800 subjects in 4 European countries (Germany, Poland, Spain and UK) representing different cultural and geographical areas of the EU as well as different levels of internet penetration. In aggregate each discrete choice experiment for topic 1, 2 and 3 was a sample of 1,600 subjects. The sample for each discrete choice experiment, 400 subjects in each country, was representative of the population that had purchased a good or service online during the last year. Quotas by gender and age were applied to these samples, based on the last available Eurostat data from the 2016 survey on ICT. The respondents for the experiment (and a pilot test) were recruited through an online panel in which an invitation email contained a link to the experiment. Screening question elicited age and gender in order to achieve the desired quotas. After the screening questions, respondents were directed to the platform where the experiment was implemented using ad hoc software created for the experimental task. Respondents completing the experiment in less than $50 \%$ of the median duration of the experiment (so called "speeders") were excluded from the final sample (circa 8\%). The time spent by the participants to complete the 
Forthcoming in Behavioural Public Policy (BPP) - Pre-print - Not final Proof

experiment was calculated as the interval of time between the time the respondent accessed the platform to the time he/she left the platform. Additional details are available in Annex 1A.

To maximise realism, ecological validity, the information (provision and prominence) was shown in realistic screenshots of mock-up websites.

The first experiment investigated three attributes of information about restaurants (i) information content, (ii) information presentation and (iii) rank position on the screen. Information content had three levels, while visual prominence of information presentation and rank position had two levels (see Table 1).

TABLE 1 ABOUT HERE

Based on different combinations of the three informational attributes and their different levels, respondents made ten choices between two restaurants featuring different attributes and attribute levels. From these choices, it is possible to infer the relative impact on the different attributes and levels of attributes on respondents' choices. Note this study was not interested in the choice of restaurant - that was merely an example of a product about which users may search for information. The focus was on the effect on choices of different information content, visual prominence and rank ordering of the search results. More specifically, we were interested in exploring the following research questions. With all other attributes held constant does an objective criterion for ranking search information influence consumer choice? (RQ1); With all other attributes held constant does a non-objective criterion for ranking search information influence consumer choice? (RQ2); With all other attributes held constant does highlighting information on the criterion for rank position 
Forthcoming in Behavioural Public Policy (BPP) - Pre-print - Not final Proof

influence consumer choice? (RQ3), and with all other attributes held constant does the rank of the information search influence consumer choice? (RQ4).

The following figures present examples of how information content attribute (see Figure 1 ), information presentation (see Figure 2) and rank position (see Figure 3) were shown to the participants.

'Figure 1 about here'

'Figure 2 about here'

'Figure 3 about here'

In the second experiment, a different group of respondents were presented with two mobile phones and asked which phone they preferred basing their evaluation of three attributes concerning contractual information and price. Here, the relevant measures followed the Guidance on the implementation/application of the Unfair Commercial Practices Directive on information about contractual entities. The three attributes were (i) information content about the contractual entity; (ii) information presented in terms of visual prominence about the contractual entity, and (iii) price of the mobile phone (Table 2). The following table shows the levels for each attribute. The design follows the logic of the study in discrete choice task 1 . In this case, the research questions were as follows. With all other attributes held constant does information on the contractual entity being a trader influence choices? (RQ5); with all other attributes held constant does information on the contractual 
Forthcoming in Behavioural Public Policy (BPP) - Pre-print - Not final Proof

entity being a trader giving the purchaser consumer rights in case of problems influence choices? (RQ6); With all other attributes held constant does highlighting information about the contractual entity influence choices? (RQ7), and with all other attributes held constant does the price of the mobile phone influence choices? (RQ8).

\section{TABLE 2 ABOUT HERE}

In similar vein to the first discrete choice task, two of the possible 12 combinations of the attribute and their levels were not feasible. With no information about the contractual entity, there can be no low or high information salience. Hence, ten combinations were presented to the respondents. The following figures present examples of how information content (IC) attribute (see Figure 4); information presentation see (Figure 5) and price (see Figure 6) were shown to the respondents.

'Figure 4 about here'

'Figure 5 about here'

'Figure 6 about here' 
The third experiment, again with a different group of respondents, investigated the effect on product selection - choice of a hotel - of user reviews. The research questions were: With all other attributes held constant does information stating that the reviewers are platform users influence choices? (RQ9); with all other attributes held constant does information stating that the reviewers have stayed at the hotel influence choices? (RQ10); with all other attributes held constant does highlighting information about reviewers' influence choices? (RQ11), and with all other attributes held constant does the quality of user reviews influence choices? (RQ12). The respondents were presented with two of the possible hotels and asked which hotel they preferred, basing their evaluation on the source of reviews received, the visual prominence of such reviews and the review rating. Table 3 outlines the levels for each attribute.

\section{TABLE 3 ABOUT HERE}

As with the previous discrete choice tasks, the following figures present examples of how information content (IC) attribute (see Figure 7); information presentation (see Figure 8) and rating (see Figure 9) were shown to the respondents.

\section{'Figure 7 about here'}

'Figure 8 about here' 
Forthcoming in Behavioural Public Policy (BPP) - Pre-print - Not final Proof

'Figure 9 about here' 


\section{Results}

The discrete choice methodology is based on random utility maximisation theory, whereby an individual is assumed to choose the utility-maximising option when presented with a choice set containing alternative scenarios. The parameter estimates are standard logit, the outcome of a conditional logistic regression with the regression coefficients representing the change in the logit for each unit change in the predictor.

\section{Information on search results}

In Table 4, we report the results of the first discrete choice experiment. Compared to having no information on the criteria for ranking search results, when informed that the ranking is based on popularity, the probability of selecting the product is $115 \%$ higher, irrespective of its ranking position and visual prominence on the screen (RQ1). Separately, when a product is ranked first on the screen, the probability of selecting it is increased by $47 \%$, irrespective of transparency about the basis of the ranking or visual prominence (RQ2, RQ3 and RQ4). It is plausible to argue that most consumers read popularity as a signal that since many others have chosen the product it must be of good quality and from a trustworthy source. It is also likely that first place in the search results carries similar connotations. Setting aside the possibility of the manipulation and/or distortion of 'popularity', the findings are evidence that information on the ranking criterion and the order in which search results are presented have a significant effect on product selection.

\section{TABLE 4 ABOUT HERE}

\section{Information on the contractual entity}

Moving to the experiment about transparency and contractual identity (Table 5), compared to having no information about the identity of contractual parties, being informed merely that the product is sold by a third-party trader reduces the probability of product selection (RQ5). However, providing the additional information that the third-party trader's status ensures 
consumer rights should there be any post-purchase problems, increases the probability of product selection over no information by almost $50 \%$ (RQ6). Partial transparency, introducing the (possibly surprising to respondents) fact that a third party is involved in the sale may lead to confusion and concerns; "can this third party be trusted?" But full transparency, the additional information that the third party's trader status provides consumer protection rights, increases the probability of purchase (RQ7). Here, full transparency is seen to increase trust and confidence in the online transaction. Price affects choice as expected, and cheaper products increase probability of selection (RQ8).

\section{TABLE 5 ABOUT HERE}

\section{Information on user reviews and ratings}

Table 6 reports the result of the experiment on user reviews and ratings. Compared to having no user reviews or ratings, a review in a prominent position on the website leads to an almost $200 \%$ increase in the probability of choosing the product (RQ11). An increase of $107 \%$ is found when the product receives the highest user rating with all other attributes held constant (RQ12). Information that the reviewers have stayed in the hotel increases the probability of choosing it by $40 \%$ (RQ10) while knowing that reviewers are merely platform users increases the chances of selection by $20 \%$ (RQ9).

\section{TABLE 6 ABOUT HERE}

Having completed one of the three experiments, respondents completed a questionnaire asking about their reactions to the information provided. Did they recall the information? Did it make them more confident and trusting in the platform? And was it important in their decisions? At least two out of three respondents said they recalled the information and of these about one in two accurately selected the correct information out of a list of options. Of those who recalled the information correctly seventy per cent or more agreed that the 
Forthcoming in Behavioural Public Policy (BPP) - Pre-print-Not final Proof

information was important in their decision and that it made them more trusting and confident in the transaction.

\section{Country comparisons}

The discrete choice experiments were conducted with respondents from Spain, Poland, Germany and the United Kingdom. To investigate country differences, we carried out the same analysis for the pooled data on each country separately. Overall, across the four countries the similarities in the pattern of results are far greater than the differences as shown in Annex 1B.

For "information search" the average estimates show a consistent picture with the exception that high prominence appears not to be significant for the German sample.

For the issue of the "contractual entity" the estimates are consistent across the four national samples with the exception of Germany where details that the contractual entity is a trader and the implications of that for consumer right is not significant while it is for the other three countries. Finally, all the estimates are similar for the four countries on "user reviews".

\section{Discussion and Conclusions}

The objective of this study was to investigate the impact of enhanced transparency on consumers' trust and behaviour in three specific areas: (1) the criteria for and presentation features of search results; (2) the identity of contractual parties, and (3) quality controls on consumer reviews, ratings, and endorsement systems. 
Forthcoming in Behavioural Public Policy (BPP) - Pre-print - Not final Proof

The results showed that the order of presentation of the search outcomes based on popularity is by far the most important attribute in increasing the probability of choosing a product. Also, ranking first in the presentation of the search results increases the probability of product selection, while the influence of the first rank is about one half of that ranking by popularity. When the explanation of the search outcomes is given high visual prominence, there is a small increase in the probability of product selection. Information that the search outcomes are ordered alphabetically does not affect the probability of choosing a product, and a lower price has the largest effect on the probability of purchasing a product. Full information that the contractual entity is a trader carrying the associated consumer rights increases the probability of the product selection. Whether information on contractual entities is visually prominent or not, it does not affect the probability of product selection. Information limited to the contractual entity being a trader, without indicating the consequences for consumer rights, reduces the probability of product selection. High visual prominence of user reviews increases the probability of selecting the product. Besides, high ratings of a product increase the probability of selection of the product. Reviews from users of the product increase the probability of selecting the product, and reviews from platform users also increase the probability of selecting the product but are less impactful than actual users of the product.

From the perspective of behavioural science, the results indicate that most people use heuristic driven forms of decision making in processing information about search results. Popularity, which is associated with the cognitive heuristic of 'social proof' (Cialdini et al., 1999), was the most powerful information cue in determining participants' choices.

Nowadays, social commerce, like business-to-consumer sites and, more importantly, intermediaries that facilitate shopping experience, continue to offer more and more innovative technologies to support interaction among like-minded community members who share the same shopping interests (Amblee \& Bui 2011). Among these technologies, reviews, ratings and recommendation systems have become some of the most important social shopping 
Forthcoming in Behavioural Public Policy (BPP) - Pre-print-Not final Proof

strategies to foster ease of use and simplicity in sharing consumption experiences and aggregating evaluations ( $\mathrm{Lu}$ et al. 2016; MacCoun 2012). The results showed that 'popularity was followed by rank position, which operates as a substitution bias (Kahneman \& Frederick 2002). Rank position is used to formulate an easy computable assessment of other attributes of a product. A similar consideration can be made regarding the issue of the contractual identity of sellers. The results indicate that providing information only about the contractual identity has a detrimental effect on product choice while including details of the scope of consumers' rights is positive.

These findings indicate that the availability heuristic may be operating in these contexts. One of the most accepted assumptions of human decision-making holds that most people make estimates and decisions based on the ease of with which instances or associations come to mind (Tversky \& Kahneman 1973). The dual-process theory of decision making provides a robust framework for investigating the psychological processes that underlie the effects that we have found (Kahneman 2011). The dual-process theory postulates that two different systems are active during decision-making processes. System 1 is considered to be fast and intuitive, while System 2 is slow and reflective. The theory suggests that purchase decision making in online environments that involve minimal risks, such as restaurant or hotel choices, are governed by System 1, making them more susceptible to systematic biases. Consumers rely on heuristics, especially in online shopping (Nazlan, Tanford, \& Montgomery 2018), where mental shortcuts simplify the decision making processes.

Information limited to contractual identity may raise the spectre of potential troubles. By contrast, full transparency with the inclusion of details on consumer rights may make future problems more salient but provide reassurance about consumer protection (Patel, Balic, \& Bwakira 2002). The final aspect of transparency concerned the user reviews, distinguishing between users that have actually purchased the product or are simply users of the platform. Results indicate a stronger effect of 'true reviewers', but the 'unverified reviewers' do have a 
positive impact on product selections. The social proof heuristic appears to be operating here, even with reviews from unverified users. It is perhaps a reminder of how automatic forms of cognition can be pervasive in decision-making contexts.

One of the strengths of the current study is that we conducted the discrete choice experiments in four European Member States with population representative samples. Second, multiple online contexts were assessed, thereby increasing external validity. To maximise ecological validity, the information (provision and prominence) was shown as realistic screenshots of mock-up websites. Third, we established whether increased transparency of different product attributes is associated with a greater impact on consumers' choices. A limitation of the current study is that participants conducted the experiment online and, as such, it was not possible to control the situation in which they participated. This is a potential threat to internal validity. However, it could also be argued that making simulated online purchases at home reflects real online purchasing decisions. Second, only a limited number of products and platforms were used in the experiments; hence, one must be cautious about generalising the findings to online behaviour in general. Nonetheless, we did not identify anything issues that would point to the expectation of different effects for other products or on other platforms.

To achieve greater online transparency leveraging behavioural insights, it is recommended that (i) action be taken to make the criteria used to order search results apparent to consumers, (ii) it is made possible to re-order search results using a range of criteria, (iii) efforts are made to raise consumers' awareness of the identity of contractual parties and their understanding of the legal implications, and (iv) platforms are encouraged to implement quality controls for improved authenticity and to achieve greater numbers of user reviews.

To conclude, the findings from the three discrete choice experiments and the postexperimental survey suggest that greater online transparency has three effects. It is important 
Forthcoming in Behavioural Public Policy (BPP) - Pre-print-Not final Proof

in decision-making; it increases trust and confidence in the online environment and, all things being equal, increases the probability of product selection. As such, online transparency is clearly in the interests of consumers. By the same token, it is in the interests of platforms which could expect to see a growth in online activity as a result of increased consumer confidence and trust. As a final note, the outcomes of this study were adopted by the European Commission's President J.C. Juncker in the New Deal for Consumers. 
Forthcoming in Behavioural Public Policy (BPP) - Pre-print - Not final Proof

\section{References}

Agnihotri, A. and S. Bhattacharya. 2016. 'Online Review Helpfulness: Role of Qualitative Factors: ONLINE REVIEW HELPFULNESS'. Psychology \& Marketing 33 (11): 1006-17. doi:10.1002/mar.20934.

Amblee, N. and T. Bui. 2011. 'Harnessing the Influence of Social Proof in Online Shopping: The Effect of Electronic Word of Mouth on Sales of Digital Microproducts'. International Journal of Electronic Commerce 16 (2): 91-114. doi:10.2753/JEC1086$\underline{4415160205}$.

Appiah, O. 2006. 'Rich Media, Poor Media: The Impact of Audio/Video vs. Text/Picture Testimonial Ads on Browsers'Evaluations of Commercial Web Sites and Online Products'. Journal of Current Issues \& Research in Advertising 28 (1): 73-86. doi:10.1080/10641734.2006.10505192.

Baek, H., J.H. Ahn, and Y. Choi. 2012. 'Helpfulness of Online Consumer Reviews: Readers' Objectives and Review Cues'. International Journal of Electronic Commerce 17 (2): 99-126. doi:10.2753/JEC1086-4415170204.

Ballantine, P. W, and C. A. Yeung. 2015. 'The Effects of Review Valence in Organic versus Sponsored Blog Sites on Perceived Credibility, Brand Attitude, and Behavioural Intentions'. Marketing Intelligence \& Planning 33 (4): 508-21. doi:10.1108/MIP-032014-0044.

Baron, D.P., and D. Besanko. 1984. 'Regulation, Asymmetric Information, and Auditing'. The RAND Journal of Economics 15 (4): 447. doi:10.2307/2555518.

Baye, M. R., B. De los Santos, and M. R. Wildenbeest. 2016. 'Search Engine Optimization: What Drives Organic Traffic to Retail Sites?: Search Engine Optimization'. Journal of Economics \& Management Strategy 25 (1): 6-31. doi:10.1111/jems.12141.

Brengman, M., and F. P. Karimov. 2012. 'The Effect of Web Communities on Consumers' Initial Trust in B2C E-commerce Websites'. Edited by Keith S. Coulter. Management Research Review 35 (9): 791-817. doi:10.1108/01409171211256569.

Chen, Y., \& He, C. (2011). Paid placement: Advertising and search on the internet. The Economic Journal, 121(556), F309-F328.

Chen, Y., S. Fay, and Q. Wang. 2011. 'The Role of Marketing in Social Media: How Online Consumer Reviews Evolve'. SSRN Electronic Journal. doi:10.2139/ssrn.1710357.

Chevalier, J. A, and D. Mayzlin. 2006. 'The Effect of Word of Mouth on Sales: Online Book Reviews'. Journal of Marketing Research, 10. 
Forthcoming in Behavioural Public Policy (BPP) - Pre-print - Not final Proof

Cialdini, R. B. 2009. Influence: science and practice. Harlow: Pearson Education.

Cialdini, R. B., W. Wosinska, D. W. Barrett, J. Butner, and M. Gornik-Durose. 1999. 'Compliance with a Request in Two Cultures: The Differential Influence of Social Proof and Commitment/Consistency on Collectivists and Individualists'. Personality and Social Psychology Bulletin 25 (10): 1242-53. doi:10.1177/0146167299258006.

Cohen, M. C. 2018. 'Big Data and Service Operations'. Production and Operations Management 27 (9): 1709-23. doi:10.1111/poms.12832.

Dal Bo, E. 2006. 'Regulatory Capture: A Review'. Oxford Review of Economic Policy 22 (2): 203-25. doi:10.1093/oxrep/grj013.

Filieri, R.. 2015. 'What Makes Online Reviews Helpful? A Diagnosticity-Adoption Framework to Explain Informational and Normative Influences in e-WOM'. Journal of Business Research 68 (6): 1261-70. doi:10.1016/j.jbusres.2014.11.006.

Flanagin, A. J, M. J Metzger, R. Pure, and A. Markov. 2011. 'User-Generated Ratings and the Evaluation of Credibility and Product Quality in Ecommerce Transactions'. In 2011 44th Hawaii International Conference on System Sciences, 1-10. Kauai, HI: IEEE. doi:10.1109/HICSS.2011.474.

Folkes, V. S. 1988. 'The Availability Heuristic and Perceived Risk'. Journal of Consumer Research 15 (1): 13. doi:10.1086/209141.

Gavilan, D., M. Avello, and G. Martinez-Navarro. 2018. 'The Influence of Online Ratings and Reviews on Hotel Booking Consideration'. Tourism Management 66 (June): 5361. doi:10.1016/j.tourman.2017.10.018.

Ghose, A., and S. Yang. 2009. 'An Empirical Analysis of Search Engine Advertising: Sponsored Search in Electronic Markets'. Management Science 55 (10): 1605-22. doi:10.1287/mnsc.1090.1054.

Hong, I. B., and H. Cho. 2011. 'The Impact of Consumer Trust on Attitudinal Loyalty and Purchase Intentions in B2C E-Marketplaces: Intermediary Trust vs. Seller Trust'. International Journal of Information Management 31 (5): 469-79. doi:10.1016/j.ijinfomgt.2011.02.001.

Hustvedt, G., and J. Kang. 2013. 'Consumer Perceptions of Transparency: A Scale Development and Validation'. Family and Consumer Sciences Research Journal 41 (3): 299-313. doi:10.1111/fcsr.12016. 
Jeacle, I., and C. Carter. 2011. 'In TripAdvisor We Trust: Rankings, Calculative Regimes and Abstract Systems'. Accounting, Organizations and Society 36 (4-5): 293-309. doi:10.1016/j.aos.2011.04.002.

Jerath, K., L. Ma, and Y.H. Park. 2014. 'Consumer Click Behavior at a Search Engine: The Role of Keyword Popularity'. Journal of Marketing Research 51 (4): 480-86. doi:10.1509/jmr.13.0099.

Kahneman, D. 2011. Thinking, fast and slow. Macmillan.

Kahneman, D., and S. Frederick. 2002. 'Representativeness Revisited: Attribute Substitution in Intuitive Judgment'. In Heuristics and Biases, edited by Thomas Gilovich Dale Griffin, and Daniel Kahneman, 1st ed., 49-81. Cambridge University Press. doi:10.1017/CBO9780511808098.004.

Kim, J., and P. Gupta. 2012. 'Emotional Expressions in Online User Reviews: How They Influence Consumers' Product Evaluations'. Journal of Business Research 65 (7): 98592. doi:10.1016/j.jbusres.2011.04.013.

Kulkarni, G., P.K. Kannan, and W. Moe. 2012. 'Using Online Search Data to Forecast New Product Sales'. Decision Support Systems 52 (3): 604-11. doi:10.1016/j.dss.2011.10.017.

Kusumasondjaja, S., T. Shanka, and C. Marchegiani. 2012. 'Credibility of Online Reviews and Initial Trust: The Roles of Reviewer's Identity and Review Valence'. Journal of Vacation Marketing 18 (3): 185-95. doi:10.1177/1356766712449365.

Litvin, Stephen W., Ronald E. Goldsmith, and Bing Pan. "Electronic word-of-mouth in hospitality and tourism management." Tourism management 29, no. 3 (2008): 458-468.

Llamero, L.. 2014. 'Conceptual Mindsets and Heuristics in Credibility Evaluation of E-Word of Mouth in Tourism'. Online Information Review 38 (7): 954-68. doi:10.1108/OIR06-2014-0128.

Lu, B., W. Fan, and M. Zhou. 2016. 'Social Presence, Trust, and Social Commerce Purchase Intention: An Empirical Research'. Computers in Human Behavior 56 (March): 22537. doi:10.1016/j.chb.2015.11.057.

Luca, M., T. Wu, S. Couvidat, D. Frank, and W. Seltzer. 2015. 'Does Google Content Degrade Google Search? Experimental Evidence'. SSRN Electronic Journal. doi: $10.2139 / \mathrm{ssrn} .2667143$.

Lupiáñez-Villanueva, F., Gaskell, G., Tornese, P., Vila, J., Gómez, Y., Allen, A., Codagnone, C. and Veltri, G. A. 2018. Behavioural study on the transparency of online platforms. 
Forthcoming in Behavioural Public Policy (BPP) - Pre-print - Not final Proof

Brussels: Office for Official Publications of the European Commission, 2018. ISBN: 978-92-9200-879-6.

Ma, Z., X. U. Liu and T. Hossain. 2013. "Effect of Sponsored Search on Consumer Trust and Choice.” IJEBM 11; n.4 pag 227-237.

Ma, Z., O. R. Sheng, G. Pant, and A. Iriberri. 2012. 'Can Visible Cues in Search Results Indicate Vendors' Reliability?' Decision Support Systems 52 (3): 768-75. doi:10.1016/j.dss.2011.12.002.

Maadi, M, M. Javidnia and M.Ghasemi, 2016. 'Applications of two new algorithms of cuckoo optimization (CO) and forest optimization (FO) for solving single row facility layout problem (SRFLP)'. 2016. Journal of Artificial Intelligence and Data Mining 4 (1). doi:10.5829/idosi.JAIDM.2016.04.01.05.

MacCoun, R. J. 2012. The burden of social proof: Shared thresholds and social influence. Psychological Review, 119(2), 345-372.

Malbon, J. 2013. 'Taking Fake Online Consumer Reviews Seriously'. Journal of Consumer Policy 36 (2): 139-57. doi:10.1007/s10603-012-9216-7.

Mayzlin, D. 2006. 'Promotional Chat on the Internet'. Marketing Science 25 (2): 155-63. doi:10.1287/mksc.1050.0137.

Mayzlin, D., Y. Dover, and J. Chevalier. 2014. 'Promotional Reviews: An Empirical Investigation of Online Review Manipulation'. American Economic Review 104 (8): 2421-55. doi:10.1257/aer.104.8.2421.

Nazlan, N. H., S. Tanford, and R. Montgomery. 2018. 'The Effect of Availability Heuristics in Online Consumer Reviews'. Journal of Consumer Behaviour 17 (5): 449-60. doi: $10.1002 /$ cb. 1731.

Patel, S. A, A. Balic, and L. Bwakira. 2002. 'Measuring Transparency and Disclosure at Firm-Level in Emerging Markets'. Emerging Markets Review 3 (4): 325-37. doi:10.1016/S1566-0141(02)00040-7.

Pew Research Centre, 2018. Accessed in February 2019 at http://www.pewinternet.org/2018/03/01/social-media-use-in-2018/pi 2018-03$\underline{01 \_ \text {social-media a- } 01 /}$

Reinstein, D. A., \& C. M. Snyder. 2005. 'The influence of expert reviews on consumer demand for experience goods: A case study of movie critics'. Journal of Industrial Economics 53 (1): 27-51.doi:10.1111/j.0022-1821.2005.00244.x. 
Forthcoming in Behavioural Public Policy (BPP) - Pre-print-Not final Proof

Rieder, B., and G. Sire. 2014. 'Conflicts of Interest and Incentives to Bias: A Microeconomic Critique of Google's Tangled Position on the Web'. New Media \& Society 16 (2): 195211. doi:10.1177/1461444813481195.

Sonntag, A. 2015. 'Search Costs and Adaptive Consumers: Short Time Delays Do Not Affect Choice Quality'. Journal of Economic Behavior \& Organization 113 (May): 64-79. doi:10.1016/j.jebo.2015.02.024.

Tambini, D. 2018 'Social media power and election legitimacy'. In: Tambini, Damian and Moore, Martin, (eds.) Digital dominance: the power of Google, Amazon, Facebook, and Apple. Oxford University Press, New York, NY, pp. 265-293. ISBN 9780190845117

Tversky, A., \& Kahneman, D. 1973. Availability: A heuristic for judging frequency and probability. Cognitive psychology, 5(2), 207-232.

Ursu, R.. 2018. The Power of Rankings: Quantifying the Effect of Rankings on Online Consumer Search and Purchase Decisions. Marketing Science, Vol. 37, No. 4: 530-552. http://dx.doi.org/10.2139/ssrn.2729325

Watt, M., \& Wu, H. 2018. 'Trust mechanisms and online platforms: A regulatory response' (Doctoral dissertation, Harvard University). 
Forthcoming in Behavioural Public Policy (BPP) - Pre-print - Not final Proof

Table 1: Task 1. Booking a restaurant experiment: attributes and levels.

\begin{tabular}{ll}
\hline Attributes & Levels \\
\hline Information content & - IC1: No information on how the search results are \\
(IC) & ranked \\
& - IC2: Information that the search results are ranked in \\
& alphabetical order (an objective criterion) \\
& - IC3: Information that the search results are ranked by \\
& popularity (a non-objective criterion). \\
Information & IP1: Low visual prominence (as a text included in the \\
presentation (IP) & header of the research results) \\
& - IP2: High visual prominence (as a highlighted text out \\
& of the header of the research results) \\
Rank Position $(R P)$ & RP1: The restaurant is ranked in first place \\
& RP2: The restaurant is ranked in the third place (out of \\
& four results of the search)
\end{tabular}


Forthcoming in Behavioural Public Policy (BPP) - Pre-print - Not final Proof

Table 2: Task 2. Transparency of contractual parties' experiment: attributes, levels and research questions

\begin{tabular}{ll}
\hline Attributes & Levels \\
\hline Information content & - IC1: No information on the contractual entity \\
(IC) & - IC2: Information on the contractual entity being a trader \\
& - IC3: Information on the contractual entity being a trader \\
& which gives the purchaser certain consumer rights in \\
& case of problems. \\
& - IP1: Low visual prominence (as a text included in the \\
Information & description of the mobile phone good) \\
presentation (IP) & IP2: High visual prominence (as a highlighted text \\
& outside the description of the mobile phone) \\
& P1: The mobile phone has a lower price \\
Price (P) & P2: The mobile phone has a higher price
\end{tabular}


Forthcoming in Behavioural Public Policy (BPP) - Pre-print - Not final Proof

Table 3: Task 3. Consumers reviews' experiment: attributes, levels and research questions

\begin{tabular}{ll}
\hline Attributes & Levels \\
\hline Information content & - IC1: No information on quality controls of reviewers \\
(IC) & - IC2: Information stating that reviewers are users of the \\
& platform \\
& - IC3: Information stating that the reviewers have stayed \\
& at the hotel. \\
& - IP1: Low visual prominence (displayed as a bullet point \\
Information & in the hotel description \\
presentation (IP) & IP2: High visual prominence (written in a coloured box \\
& under the hotel description) \\
& - R1: The hotel attracts the highest user review \\
Rating (R) & R2: The hotel attracts the lowest user review \\
\hline
\end{tabular}


Forthcoming in Behavioural Public Policy (BPP) - Pre-print - Not final Proof

Table 4. Search results experiment: Booking a restaurant $(n=1600)$

\begin{tabular}{|c|c|c|c|c|c|c|}
\hline Attribute and level & $\begin{array}{l}\text { Estimat } \\
\mathrm{e} \\
\text { (Logit) }\end{array}$ & $\begin{array}{l}\text { Probability } \\
1\end{array}$ & $\%$ & $\begin{array}{l}\text { Std. } \\
\text { Error }\end{array}$ & $\begin{array}{l}\mathrm{t}- \\
\text { value }\end{array}$ & $\operatorname{Pr}(>|t|)$ \\
\hline $\begin{array}{l}\text { IC3: Information on the } \\
\text { search results reflects } \\
\text { 'popularity' }\end{array}$ & 0.77 & 2.15 & $+115 \%$ & 0.02 & $\begin{array}{l}26.1 \\
5\end{array}$ & $\begin{array}{l}<2.2 \mathrm{e}- \\
16\end{array}$ \\
\hline $\begin{array}{l}\mathrm{RP} 1 \text { : The restaurant is } \\
\text { ranked in first place }\end{array}$ & 0.39 & 1.47 & $+47 \%$ & 0.02 & $\begin{array}{l}17.0 \\
8\end{array}$ & $\begin{array}{l}<2.2 \mathrm{e}- \\
16\end{array}$ \\
\hline IP2: High prominence & 0.15 & 1.16 & $+16 \%$ & 0.02 & 6.25 & $\begin{array}{l}4.033 \mathrm{e}- \\
10\end{array}$ \\
\hline $\begin{array}{l}\text { IC2: Information on the } \\
\text { search results in } \\
\text { alphabetical order. }\end{array}$ & -0.09 & 0.91 & $-9 \%$ & 0.03 & -2.63 & 0.0084 \\
\hline
\end{tabular}

Table 5. Contractual entities experiment: buying a mobile phone $(n=1600)$.

\begin{tabular}{lllllll}
\hline Attribute and level & $\begin{array}{l}\text { Estima } \\
\text { te }\end{array}$ & $\begin{array}{l}\text { Probabili } \\
\text { ty }\end{array}$ & & $\begin{array}{l}\text { Std. } \\
\text { Error }\end{array}$ & $\begin{array}{l}\text { t- } \\
\text { value }\end{array}$ & Pr $(>|\mathrm{t}|)$ \\
\hline $\begin{array}{l}\text { P1: The good has a lower } \\
\text { price }\end{array}$ & 1.04 & 2.82 & $+182 \%$ & 0.02 & 41.97 & $<2.2 \mathrm{e}-16$ \\
$* * *$
\end{tabular}


Forthcoming in Behavioural Public Policy (BPP) - Pre-print - Not final Proof

\begin{tabular}{lllllll}
\hline $\begin{array}{l}\text { IP2: High visual } \\
\text { prominence }\end{array}$ & -0.01 & 0.99 & $-1 \%$ & 0.02 & -0.39 & 0.6941 \\
& & & & & & \\
$\begin{array}{l}\text { IC2: Information on the } \\
\text { contractual entity being } \\
\text { third party trader }\end{array}$ & -0.18 & 0.83 & $-17 \%$ & 0.03 & -5.44 & $5.325 \mathrm{e}-08$ \\
\end{tabular}

Note. Baselines: No info on contractual entity; low visual prominence; lower price

Table 6. User reviews experiment: booking a hotel $(n=1600)$.

\begin{tabular}{|c|c|c|c|c|c|c|}
\hline Attributes and levels & $\begin{array}{l}\text { Estimat } \\
\mathrm{e}\end{array}$ & Probability & $\%$ & $\begin{array}{l}\text { Std. } \\
\text { Error }\end{array}$ & $\begin{array}{l}\mathrm{t}- \\
\text { value }\end{array}$ & $\operatorname{Pr}(>|t|)$ \\
\hline IP2: High visual prominence & 1.09 & 2.97 & $\begin{array}{l}+197 \\
\%\end{array}$ & 0.02 & 39.58 & $\begin{array}{l}<2.2 \mathrm{e}- \\
16\end{array}$ \\
\hline $\begin{array}{l}\text { Q1: The good or service has the } \\
\text { highest user review }\end{array}$ & 0.73 & 2.07 & $\begin{array}{l}+107 \\
\%\end{array}$ & 0.02 & 30.17 & $\begin{array}{l}<2.2 \mathrm{e}- \\
16\end{array}$ \\
\hline $\begin{array}{l}\text { IC3: Information stating that the } \\
\text { reviewers have actually bought } \\
\text { and use the good or service } \\
\text { system }\end{array}$ & 0.34 & 1.40 & $+40 \%$ & 0.03 & 11.44 & $\begin{array}{l}<2.2 \mathrm{e}- \\
16\end{array}$ \\
\hline $\begin{array}{l}\text { IC2: Information stating that } \\
\text { reviewers are just users of the } \\
\text { platform }\end{array}$ & 0.18 & 1.20 & $+20 \%$ & 0.03 & 5.03 & $\begin{array}{l}4.812 \mathrm{e}- \\
07\end{array}$ \\
\hline
\end{tabular}

Note. Baselines: no info on quality controls on reviews; low visual prominence; hotel attracts low user review 
Figure 1. Search result experiment: example of information content attribute

\section{Booking a table in a restaurant}

Suppose that you want to book a table in an Indian restaurant in Paris through an online platform. You have searched 'Indian restaurant in Paris' in two booking platforms, named Restaurantbook and Restaurantfinder, obtaining the following results. Please tell us if you prefer to make a reservation in:

\section{Q Click on the image to enlarge}
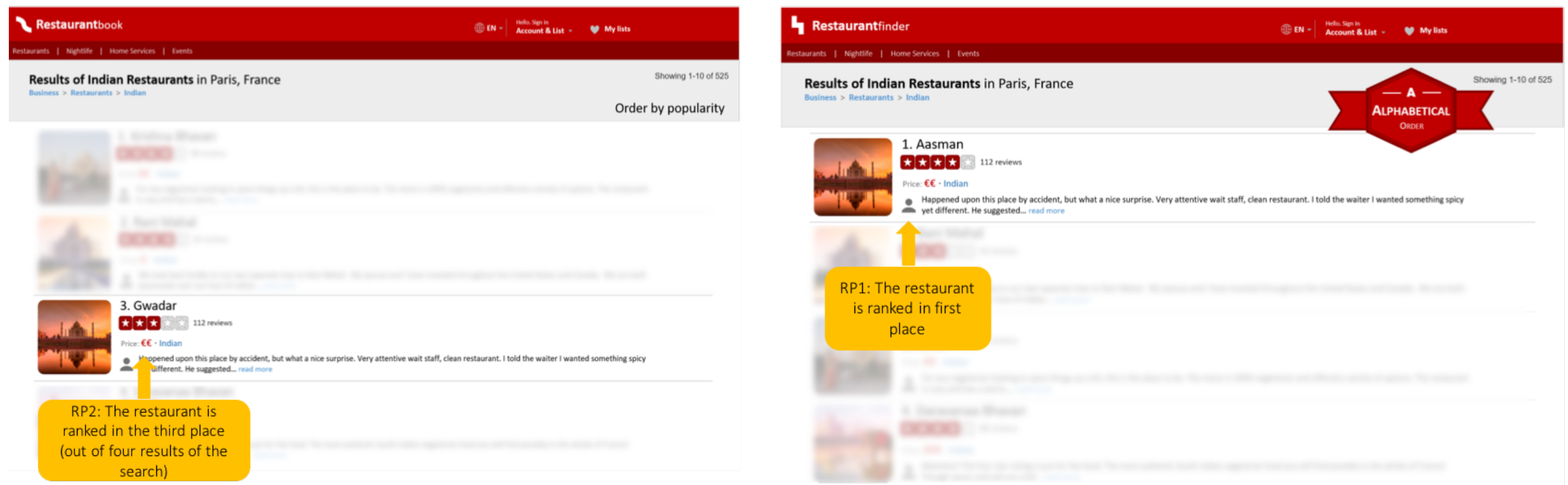
Figure 2. Search result experiment: example of information presentation

\section{Booking a table in a restaurant}

Suppose that you want to book a table in an Indian restaurant in Paris through an online platform. You have searched 'Indian restaurant in Paris' in two booking platforms, named Restaurantbook and Restaurantfinder, obtaining the following results. Please tell us if you prefer to make a reservation in:

Q Click on the image to enlarge
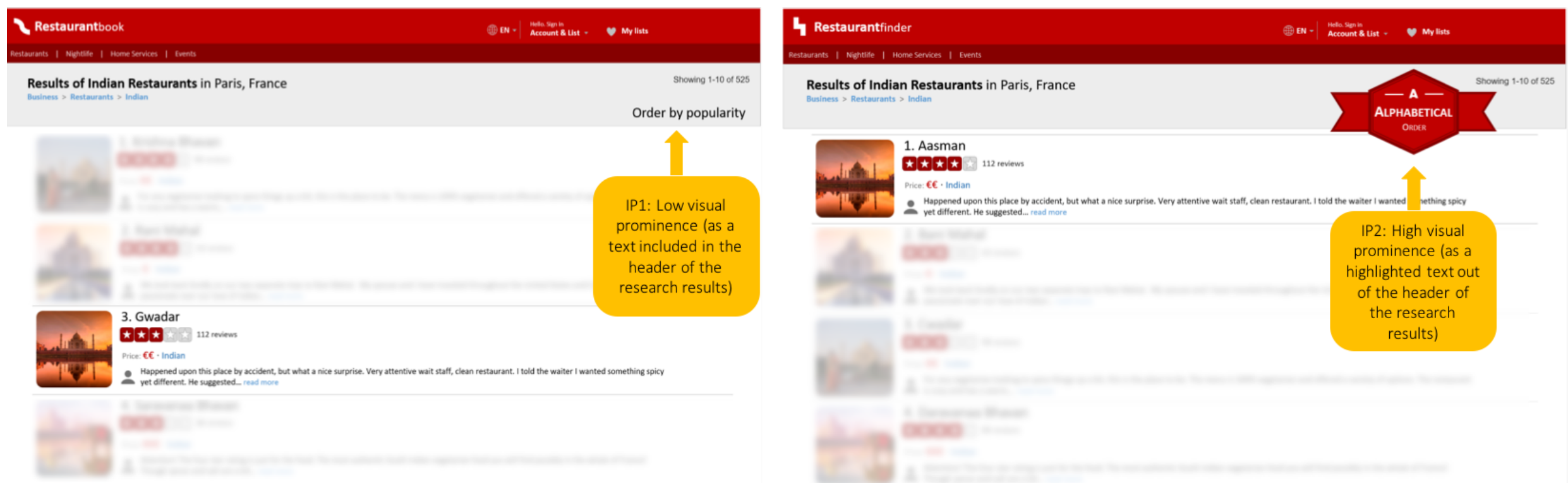
Figure 3. Search result experiment: example of rank position

\section{Booking a table in a restaurant}

Suppose that you want to book a table in an Indian restaurant in Paris through an online platform. You have searched 'Indian restaurant in Paris' in two booking platforms, named Restaurantbook and Restaurantfinder, obtaining the following results. Please tell us if you prefer to make a reservation in:

\section{@ Click on the image to enlarge}

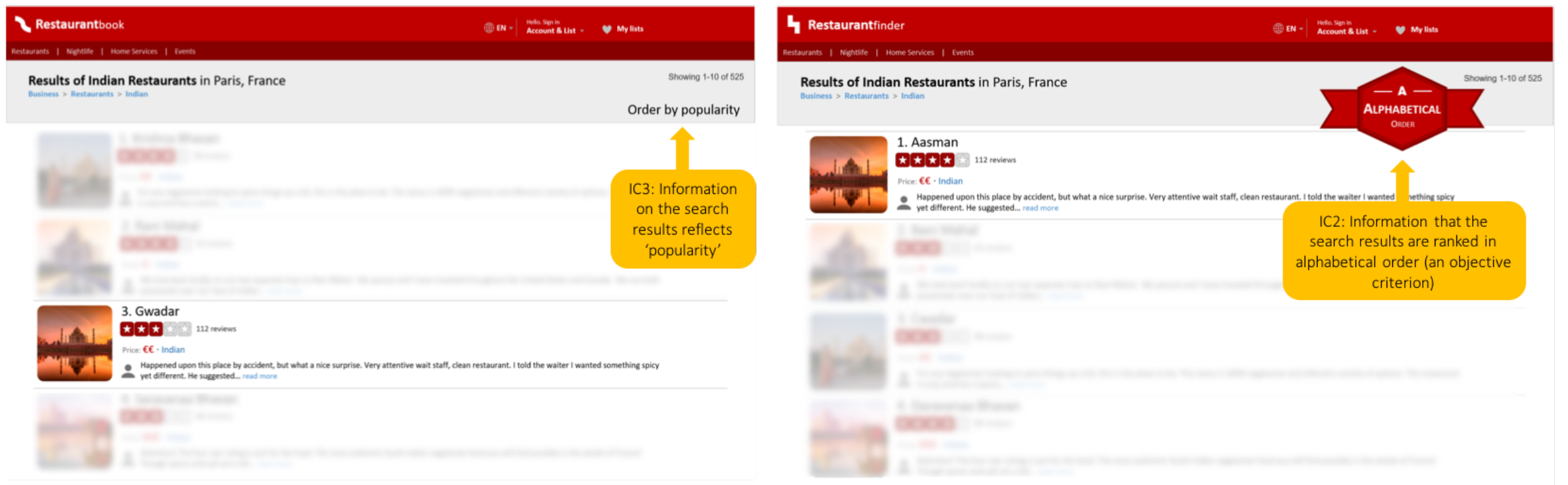


Figure 4. Identity of contractual parties experiment: example of information content attribute and levels

\section{Purchasing a smartphone}

Suppose that you want to buy a smartphone with some specific technical characteristics. Two e-commerce platforms, named Phonefinder and Phonequest, offer the two following smartphones with the required characteristics. Please tell us if you prefer to buy:

\section{Q Click on the image to enlarge}

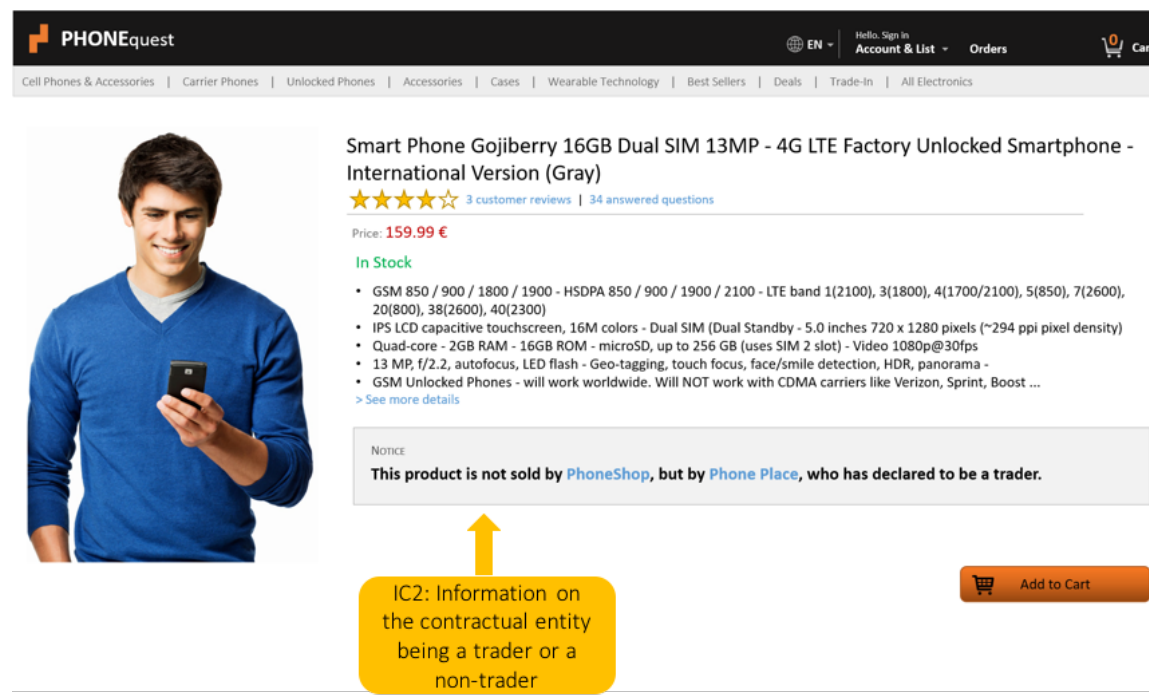

2 PHONEshop

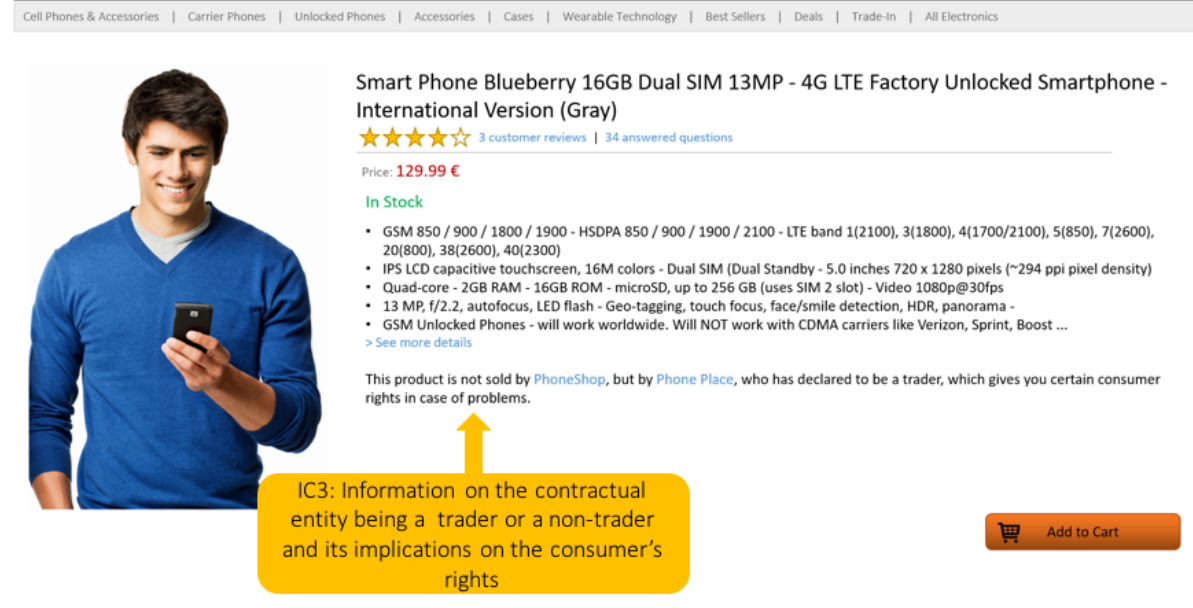


Figure 5. Identity of contractual parties' experiment: example of information presentation attribute and levels

\section{Purchasing a smartphone}

Suppose that you want to buy a smartphone with some specific technical characteristics. Two e-commerce platforms, named Phonefinder and Phonequest, offer the two following smartphones with the required characteristics. Please tell us if you prefer to buy:

\section{Q Click on the image to enlarge}

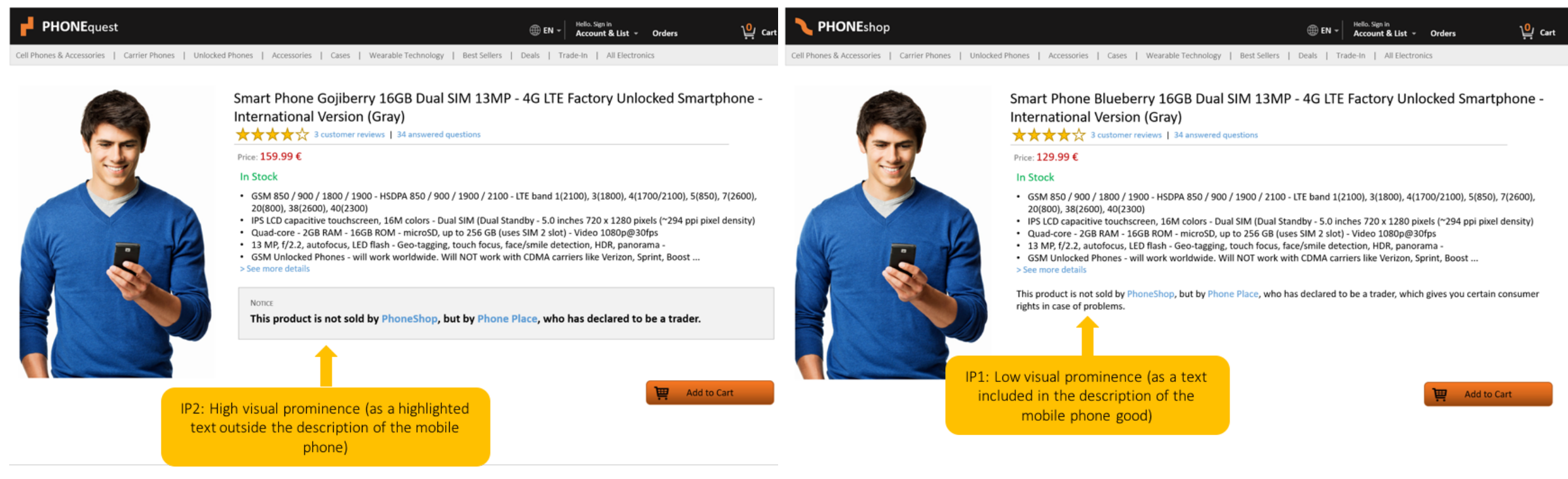


Figure 6. Identity of contractual parties' experiment: example of price

\section{Purchasing a smartphone}

Suppose that you want to buy a smartphone with some specific technical characteristics. Two e-commerce platforms, named Phonefinder and Phonequest, offer the two following smartphones with the required characteristics. Please tell us if you prefer to buy:

\section{Q Click on the image to enlarge}
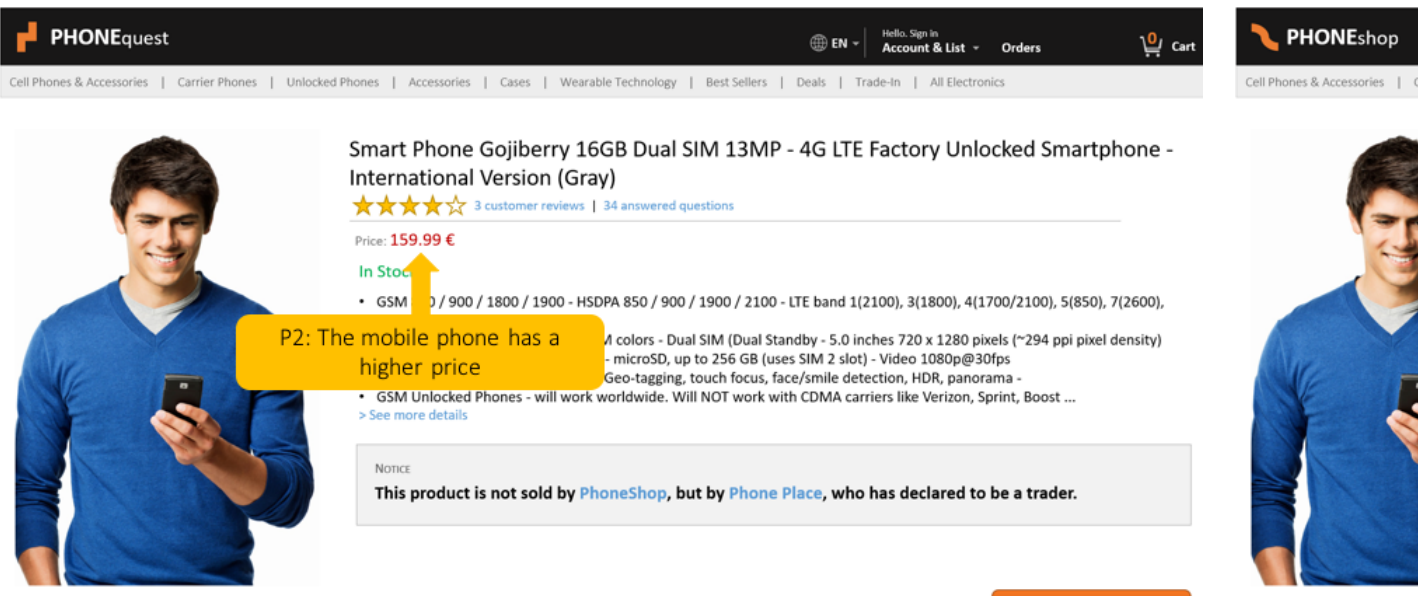

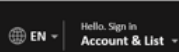
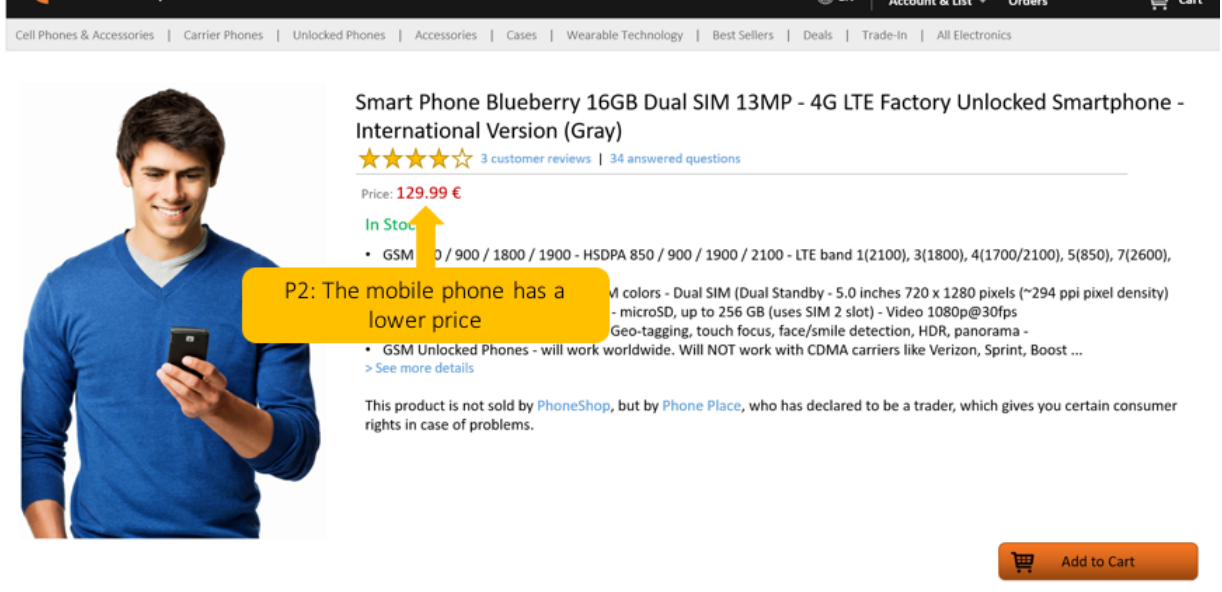
Figure 7. Review result experiment: example of information content attribute and levels

\section{Booking a room hotel}

Suppose that you want to make a reservation hotel in central Paris (1st arrondissement) through an online platform. Two booking platforms, named Hotelbook and Hotelfinder, offer the following hotels in the required area of Paris. Please tell us if you prefer to make a reservation in:

Q Click on the image to enlarge

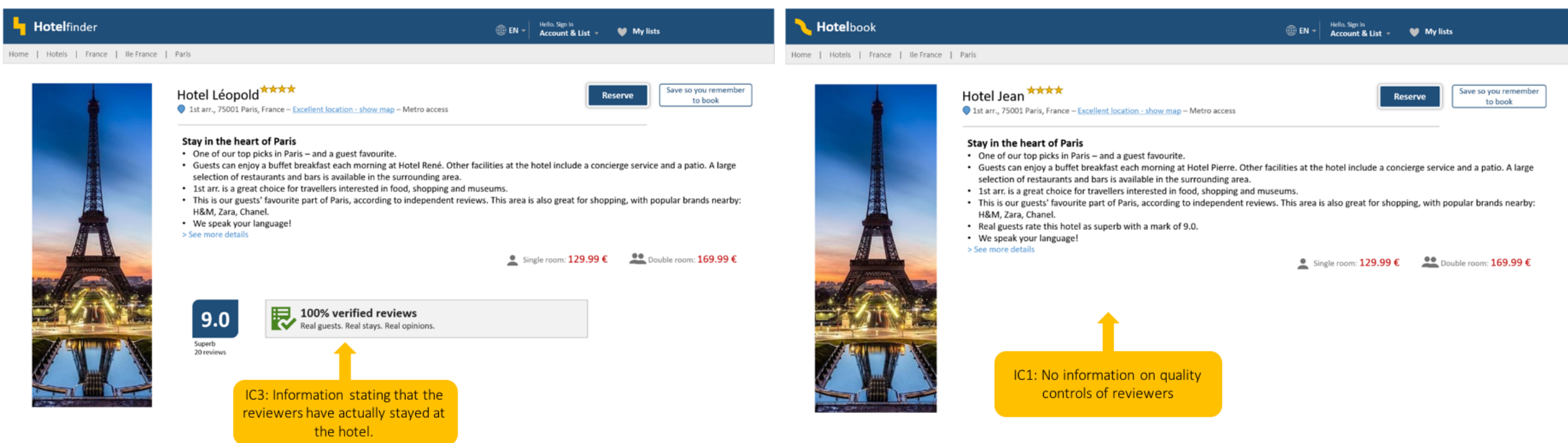


Figure 8. Review result experiment: example of information presentation attribute and levels

\section{Booking a room hotel}

Suppose that you want to make a reservation hotel in central Paris (1st arrondissement) through an online platform. Two booking platforms, named Hotelbook and Hotelfinder, offer the following hotels in the required area of Paris. Please tell us if you prefer to make a reservation in:

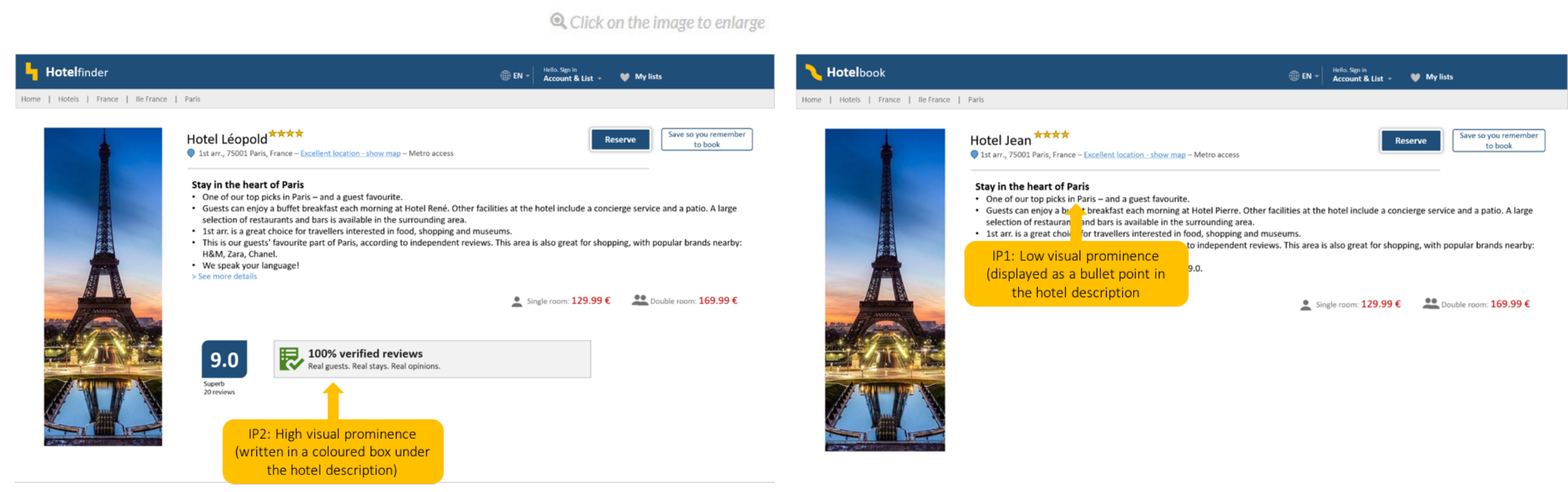


Figure 9. Review result experiment: example of rating review attribute and levels

\section{Booking a room hotel}

Suppose that you want to make a reservation hotel in central Paris (1st arrondissement) through an online platform. Two booking platforms, named Hotelbook and Hotelfinder, offer the following hotels in the required area of Paris. Please tell us if you prefer to make a reservation in:

Q Click on the image to enlarge
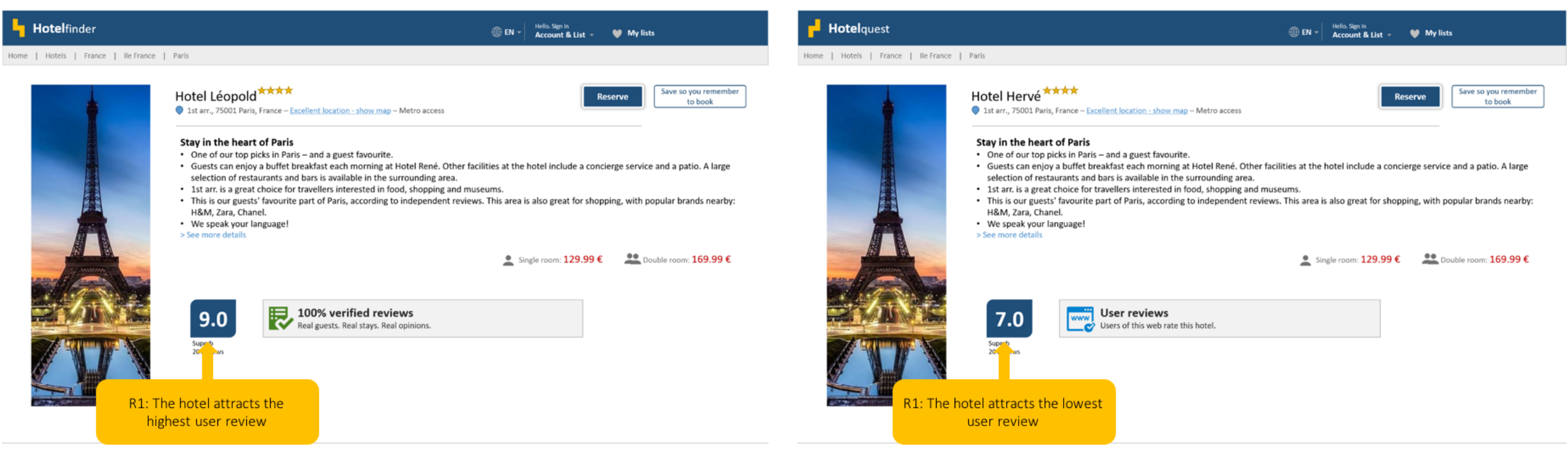
Forthcoming in Behavioural Public Policy (BPP) - Pre-print - Not final Proof 